\title{
Autoantibody and idiotype profile of lung involvement in autoimmune rheumatic disease
}

\author{
L Turner-Stokes, P Haslam, M Jones, C Dudeney, S Le Page, D Isenberg
}

\begin{abstract}
Several reports have linked the presence of certain serum autoantibodies with particular clinical manifestations of autoimmune disease. For example, the Jo-1 antibody is now established as a marker for fibrosing alveolitis in polymyositis. To investigate the possible association of further autoantibodies or idiotypes with fibrosing alveolitis in autoimmune rheumatic disease a panel of autoantibodies was measured in serum samples from 28 patients with systemic lupus erythematosus (SLE) (10 with and 18 without lung involvement), 21 patients with scleroderma (12 with fibrosing alveolitis and nine without), and 41 patients with 'lone' fibrosing alveolitis. Antibodies measured were IgM and IgG antidsDNA and anti-ssDNA antibody; IgG and IgM anticardiolipin antibody; anti-poly (ADPribose) antibody; antibodies to two common idiotypes of anti-DNA antibodies, designated 134 and 16/6; and IgM, IgG, and IgA isotypes of rheumatoid factor.

None of these antibodies was specifically associated with lung involvement in SLE or scleroderma, but a trend was found towards an increase in all autoantibodies in association with lung disease in SLE, while the reverse trend was seen in scleroderma.
\end{abstract}

Cryptogenic fibrosing alveolitis is known to occur alone or in association with autoimmune rheumatic diseases. Immunological abnormalities are commonly found in patients in whom fibrosing alveolitis is associated with these diseases, but also occur in patients with fibrosing alveolitis alone ('lone' fibrosing alveolitis). Chapman et al reported positive antinuclear antibodies in $46 \%$ of patients with fibrosing alveolitis with connective tissue disease, compared with $21 \%$ of patients with 'lone' fibrosing alveolitis, and $6 \%$ of normal control

Conversely, within specific categories of autoimmune rheumatic disease, lung involvement with the histological features of fibrosing alveolitis may only affect some patients. ${ }^{2}$ It is thus pertinent to ask whether the development of fibrosing alveolitis in these patients is related

Antinuclear antibodies can recognise a number of different nuclear antigens, and antibodies to a wide range of autoantigens and idiotypes are now identified in serum samples from patients with most autoimmune rheumatic diseases. Several reports have linked the presence of certain serum autoantibodies with particular clinical manifestations of autoimmune disease. For instance, anti-double-stranded DNA antibodies are correlated with renal involvement in systemic lupus erythematosus (SLE) ${ }^{3}$ anti-Ro antibodies with the neonatal lupus syndrome, ${ }^{4}$ and anti-La antibodies are strongly associated with Sjögren's syndrome. ${ }^{5}$ The Jo-l antibody is found almost exclusively in patients with polymyositis. ${ }^{6}$ Although present in only about $30 \%$ of patients with polymyositis, however, the Jo-l antibody has been found in $70 \%$ of patients with a combination of myositis and fibrosing alveolitis. ${ }^{7}$ Several studies have attempted to link pulmonary involvement in SLE and scleroderma with autoantibody production. One series reported anti-Ro antibodies in association with pneumonitis in antinuclear antibody negative lupus, ${ }^{8}$ but other reports found no association, either in SLE or in scleroderma. ${ }^{910}$ In contrast, anti-Scl-70 antibodies have been associated with pulmonary interstitial fibrosis in scleroderma - even though only $25 \%$ of these patients express this antibody. ${ }^{11}$ The association of anticentromere antibodies in scleroderma is not as clear cut. Steen et al showed that patients with scleroderma with anticentromere antibodies less often had pulmonary involvement but, somewhat paradoxically, the prevalence of pulmonary hypertension was similar in anticentromere antibody positive and negative patients with limited forms of the disease. ${ }^{11}$

To investigate the possible association of further nuclear autoantibodies or idiotypes with lung involvement, especially fibrosing alveolitis, in other autoimmune conditions, a panel of autoantibodies was assayed in serum samples from patients with 'lone' fibrosing alveolitis; patients with scleroderma, with and without fibrosing alveolitis; and patients with SLE, with major recurrent pleural effusions.

\section{Patients and methods}

PATIENTS

The table shows the groups of patients selected. All patients with autoimmune rheumatic disease fulfilled the 1982 revised American Rheumatism Association criteria for the classification of SLE, ${ }^{12}$ or systemic sclerosis (scleroderma). ${ }^{13}$ 'Lone' fibrosing alveolitis was diagnosed in patients who did not have clinical features to suggest extrapulmonary connective tissue disease. In 'lone' fibrosing alveolitis and scleroderma the presence of fibrosing alvelolitis was determined by radiological features and abnormal lung function tests, and confirmed by biopsy. In the group with SLE six patients had subjects. ${ }^{1}$ to their autoantibody profile.

Department of
Rheumatology Research,
University
College/Middlesex
Hospital School of
Medicine, London
L Turner-Stokes
M Jones
C Dudeney
S Le Page
D Isenberg
National Heart and
Lung Institute,
Brompton Hospital,
London
P Haslam
Correspondence to:
Dr David A Isenberg,
Department of Rheumatology
Research, Arthur Stanley
House, Tottenham Street,
London W1P 9PG.
Accepted for publication
I June 1989


Number of patients studied in each group

\begin{tabular}{llll}
\hline & $\begin{array}{l}\text { With } \\
\text { lung disease }\end{array}$ & $\begin{array}{l}\text { Without } \\
\text { lung disease }\end{array}$ & Total \\
\hline 'Lone' CFA ${ }^{*} \dagger$ & & & \\
ANAt positive & 17 & - & 41 \\
ANA negative & 24 & 18 & 28 \\
SLE† & 10 & 9 & 21 \\
Scleroderma & 12 & 27 & 90 \\
Total & 63 & &
\end{tabular}

* Patients without clinical evidence of extrapulmonary autoimmune disease.

tCFA=cryptogenic fibrosing alveolitis; $A N A=$ antinuclear antibody; SLE=systemic lupus erythematosus.

radiological and physiological evidence of pulmonary fibrosis, and four patients were included who had lung involvement other than fibrosing alveolitis-namely, major recurrent pleural effusions.

\section{METHODS}

The following serum autoantibodies were measured by methods previously described: IgM and IgG anti-dsDNA and anti-ssDNA antibody ${ }^{14}$; IgG and IgM anticardiolipin antibody $^{15}$; anti-poly(ADP-ribose) antibody ${ }^{16}$; antibodies to two common idiotypes of anti-DNA antibodies, designated $134^{12}$ and $16 / 6^{17}$; and $\operatorname{Ig} M$, IgG, and IgA isotypes of rheumatoid factor. ${ }^{18}$ In each case the results were expressed as a percentage of a known high positive serum, and the upper limits of normal range set as mean $+2 \mathrm{SD}$ for a control population of normal healthy individuals.

\section{Results}

Figures 1, 2, and 3 show the number of patients in each group with the various autoantibodies and idiotypes.

In this group of patients with 'lone' fibrosing alveolitis $17(41 \%)$ were antinuclear antibody positive and $24(59 \%)$ were antinuclear antibody negative. There was little evidence for the particular autoantibodies or idiotypes described here, even among the antinuclear antibody positive patients. Only anti-poly(ADP-ribose) and anticardiolipin antibodies were found in more than $10 \%$ of patients (fig 1 ).

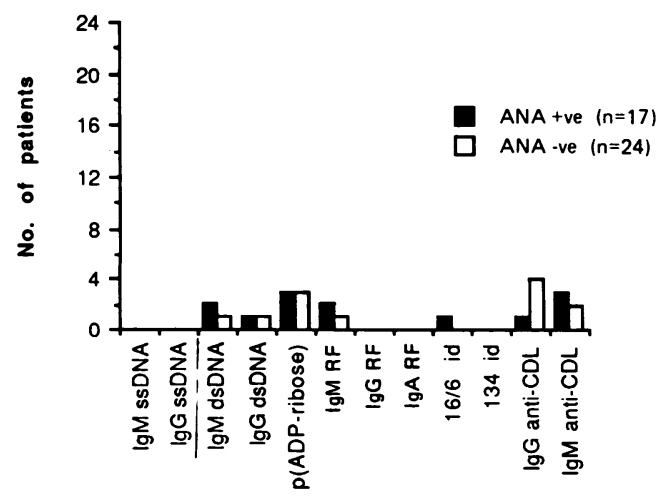

Figure 1: Serum autoantibodies and idiotypes in 'lone' cryptogenic fibrosing alveolitis. ANA = antinuclear antibody; $R F=$ rheumatoid factor $;$ id $=$ idiotype anti-CDL $=$ anticardiolipin.

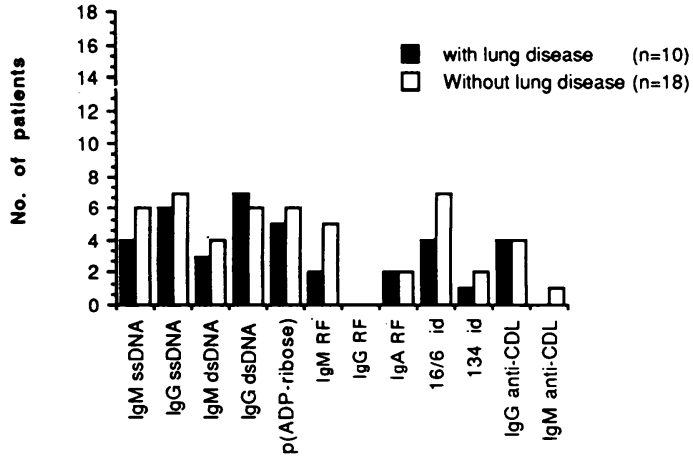

Figure 2: Serum autoantibodies and idiotypes in patients with systemic lupus erythematosus. $R F=$ rheumatoid factor; id=idiotype; anti-CDL=anticardiolipin.

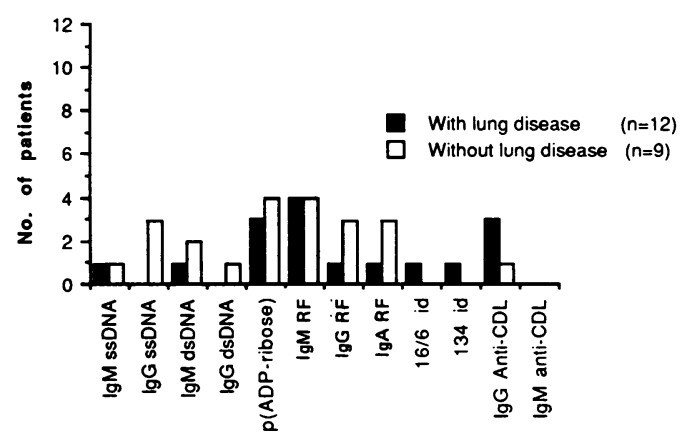

Figure 3: Serum autoantibodies and idiotypes in scleroderma. $F A=$ fibrosing alveolitis; $R F=$ rheumatoid factor; id=idiotype; anti-CDL=anticardiolipin.

Among the patients with SLE, antibodies binding to double and single stranded DNA were more prevalent among patients with lung involvement, though the difference was only significant $(p<0.05)$ for IgG antibodies to dsDNA. Indeed, there was a trend towards higher prevalence of all antibodies in those with lung involvement compared with those without (fig 2).

Interestingly, the reverse trend was seen in the patients with scleroderma. Here, autoantibodies, especially IgG and IgA isotypes of rheumatoid factor, and IgG anti-DNA antibodies, were mainly found in the patients who did not have fibrosing alveolitis (fig 3).

\section{Discussion}

In this study none of the autoantibodies or idiotypes that was measured emerged as a marker for fibrosing alveolitis in SLE or scleroderma, as Jo-1 appears to in polymyositis.

Nevertheless, there was a trend towards an increase in all of the antinuclear antibodies in association with lung disease in SLE, while the reverse trend was seen in scleroderma. There are several possible explanations for this finding.

In SLE active disease is reported to be associated with a rise in titre of certain autoantibodies. For example, high titres of antidsDNA antibodies are often seen in active renal disease. In our group of patients those with lung involvement might also have had more active disease. By contrast, those in the group with scleroderma with fibrosing alveolitis might have been less active at the time of study. 
Alternatively, the difference may reflect different pathogenesis of lung involvement in SLE and scleroderma. Immune complex deposition resulting in fibrosing alveolitis in SLE might be expected to occur in the presence of increased immunoglobulin synthesis, reflected particularly in increased levels of IgG antibodies to ssDNA and dsDNA. In scleroderma, on the other hand, increased fibroblastic activity, producing a similar end result of fibrosing alveolitis, may occur by an entirely different mechanism.

Finally, the differences may simply reflect the comparatively small number of patients in some of the groups. With these small numbers only trends rather than statistical differences could be found. If there was a true difference between the groups one might also have expected to see a difference in antibody titres between the groups with and without fibrosing alveolitis, and this was not found.

These results suggest that although none of the autoantibodies or idiotypes measured here were specifically associated with the presence of fibrosing alveolitis in SLE or scleroderma, there may be more generalised differences in the autoantibody profiles of patients with and without lung involvement, and these may reflect activity of disease, or the mechanisms by which fibrosing alveolitis is produced. A larger study, encompassing a wider range of autoantibodies, is clearly indicated.

The authors wish to thank the patients, and also Dr Carol Black (West Middlesex Hospital) and Professor Margaret TurnerWarwick (Brompton Hospital) for providing serum samples.

1 Chapman J R, Charles P J, Venables P J W, et al. Definition and clinical relevance of antibodies to nuclear ribonucleoprotein and other nuclear antigens in patients with cryptogenic fibrosing alveolitis. Am Rev Respir Dis 1984; 130: genic fibro. 43.
2 Turner-Stokes L, Turner-Warwick M. Intra-thoracic manifestations of SLE. Clin Rheum Dis 1982; 8: 229-42.

3 Cameron J S, Levof M H, Ogg C S, Williams B D, Williams D G. Disease activity in the nephritis of systemic lupus erythematosus in relation to serum complement concentrations, DNA-binding capacity, and precipitating anti-DNA tions, DNA-binding capacity, and precipitating
antibody. Clin Exp Immunol 1976; 25: 418-27.

4 Scott J S, Maddison P J, Taylor P V, Esscher E, Scott O, Skinner R P. Connective tissue disease, antibodies to ribonuclear protein, and congenital heart block. $N$ Engl $\mathcal{F}$ Med 1983; 309: 209-12.

5 Maddison P J, Isenberg D A, Goulding N, Leddy J, Skinner R P. Anti-La (SS-B) identifies a distinctive subgroup of SLE. $B r \mathcal{F}$ Rherumatol 1988; 17: 27-31.

6 Nishikai M, Reichlin M. Heterogeneity of precipitating antibody systems in polymyositis and derematomyositis. Characterisation of the Jo-1 antibody system. Arthritis Rheum 1980; 23: 881-8.

7 Yoshida S, Akizuki M, Mimori T, Yamagata H, Inada S Homma $M$. The precipitating antibody to an acidic nuclear Homma $M$. The precipitating antibody to an acidic nuclear
protein antigen, the Jo- 1 , in connective tissue diseases. A protein antigen, the Jo-1, in connective tissue diseases. A
marker for a subset of polymyositis with interstitial pulmarker for a subset of polymyositis with interstital

8 Hedgpeth M T, Boulware D W. Interstitial pneumonitis in antinuclear antibody-negative systemic lupus erythematosus; a new clinical manifestation and possible association with anti-Ro (SS-A) antibodies. Arthritis Rheum 1988; 31: 545-8.

9 Mond C B, Peterson M G E, Rothfield N F. Correlation of anti-Ro antibody with photosensitive rash in systemic lupus erythe

10 Pereira S, Black C, Welsh K, et al. Auto-antibodies and immunogenetics in 30 patients with systemic sclerosis and immunogenetics in 30 patients with systemic

11 Steen D S, Powell D L, Medsger T A Jr. Clinical correlations and prognosis based on serum auto-antibodies in patient with systemic sclerosis. Arthritis Rheum 1988; 31: 196-203.

12 Tan E M, Cohen A S, Fries J F, et al. The 1982 revised criteria for the classification of systemic lupus erythematosus. Arthritis Rheum 1982; 25: 1271-7.

13 Masi A T, Rodnan G P, Medsger T A, et al. Preliminary criteria for the classification of systemic sclerosis (scleroderma). Bull Rheum Dis 1981; 31: 1-6.

14 Isenberg D A, Dudeney S, Williams W, et al. Measuremen of anti-DNA antibodies: a reappraisal using five different methods. Ann Rheum Dis 1987; 46: 448-56.

15 Isenberg D A, Williams W, Le Page S, et al. A comparison of autoantibodies and common DNA idiotypes in SLE of autoantibodies and common DNA idiotypes in SLE patients

16 Dudeney C, Shoenfeld Y, Rauch J, et al. Antibodies to poly (ADP-ribose) and the idiotype 134 in lupus family members. Ann Rheum Dis 1986; 45: 502.

17 Isenberg D A, Shoenfeld Y, Madaio M P, et al. Anti-DNA antibody idiotypes in SLE. Lancet 1984; ii: $417-22$.

18 Isenberg D A, Maddison P J, Swana G, et al. Profile of autoantibodies in the serum of patients with tuberculosis, klebsiella and other gram negative infections. Clin Exp Immunol 1987; 67: 516-23. 